\title{
Index of orthodontic treatment needs (IOTN) on orthodontic patients at post graduate orthodontics
}

\author{
Nurul Amalina Othman*, Jono Salim*, Avi Laviana* \\ ${ }^{*}$ Department of Orthodontics, Faculty of Dentistry, Universitas Padjadjaran
}

\begin{abstract}
Introduction: Index of Orthodontic Treatment Need (IOTN) was first developed by Brook and Shaw (1989) as a system for grading malocclusions, has 2 components, AC (Aesthetic Component) that shows patient's subjective needs and DHC (Dental Heath Component) that reveals objective needs for orthodontic treatment. The objective of this research was to know the severity of malocclusion based on IOTN index of orthodontic patients at Post Graduate Orthodontic Clinic Faculty of Dentistry Universitas Padjadjaran from year 2009 to 2010 . Method: This descriptive research was done by using data from dental study models of the patients and anterior scale photographs of the patients from the Orthodontic PPDGS students, Faculty of Dentistry Universitas Padjadjaran. Result: The result of this research shows DHC $59.63 \%$ of the patients had definite need for treatment, while $27.52 \%$ of the patients had borderline need for treatment and the rest $12.85 \%$ of the patients had no need or little need for orthodontic treatment. Meanwhile, according to AC, $49.54 \%$ of the patients had no need or little need for treatment, while $33.03 \%$ of the patients had definite need for treatment and $17.43 \%$ of the patients expressed borderline need for treatment. Conclusion: In a nut shell, by using DHC of IOTN, the highest percentage of patients is in definite need for treatment category. However by using AC of IOTN, the highest percentage of patients is in no need or little need for treatment category.
\end{abstract}

Keywords: IOTN, DHC, AC.

\section{INTRODUCTION}

The awareness for acceptable dental appearance is giving a distinctive recognition to orthodontics in the field of dentistry. As the individual esthetic consciousness has been increasing, the demand for orthodontic treatment has also been increasing with time. ${ }^{1,2}$ Demand for orthodontic treatment is mainly motivated by a concern for, and a desire to, improve appearance. ${ }^{3}$

Effective control of oral and dental health requires collecting accurate data on the needs of the society in this regard. Having accurate epidemiologic information about orthodontic treatment needs is a necessity for public health centers like dentistry schools. ${ }^{4}$ Various studies on determination of orthodontic treatment needs are carried out on the basis of IOTN (Index of Orthodontic Treatment Need) in different countries, such as United Kingdom ${ }^{5}$, Tanzania ${ }^{6}$, Peru $^{7}$, France ${ }^{8}$, Sweden ${ }^{9}$ and Iran. ${ }^{10}$

In Jordan, a sample of 1002 students aged 12-14 years were examined using IOTN and found that 33 percent of students showed a great need for orthodontic treatment. ${ }^{1}$ In all reported studies, the demand for orthodontic treatment was higher

Corresponding author: Avi Laviana, Department of Orthodontics, Faculty of Dentistry Universitas Padjadjaran, Indonesia. Jalan Sekeloa Selatan I, Bandung, West Java, Indonesia, 40132; Phone: +6222-2504985/2532805 
than the actual need. In Peru, Bernabe and $\mathrm{Mir}^{7}$ examined using IOTN index, 281 university students and reported that 29.9 percent of students were in great need of treatment. ${ }^{7}$

The assessment of orthodontic treatment need based on IOTN has gained international acceptance in recent years because it was found to be valid, reliable and easy to use. ${ }^{11}$ IOTN index has proven to be an effective screening tool to determine the priority of orthodontic treatment need. ${ }^{12}$ IOTN is chosen as the index to assess orthodontic treatment need in this research because it is the most common and popular index and it has been applied world widely.

This research has been done using samples from orthodontic patients at Post Graduate Orthodontic Clinic Faculty of Dentistry Universitas Padjadjaran. The reason why Orthodontic Clinic Faculty of Dentistry Universitas Padjadjaran is chosen in this research is because this clinic is the biggest dental clinic in Bandung, and the cost of treatment is fairly cheaper than other private dental clinics. Thus, majority of people in Bandung would prefer to receive treatment from Clinic of Dentistry Universitas Padjadjaran. The objective is to know the severity of malocclusion based on IOTN index of orthodontic patients at Post Graduate Orthodontic Clinic Faculty of Dentistry Universitas Padjadjaran from year 2009 to 2010.

\section{METHODS}

The type of research conducted is descriptive based on Index of Orthodontic Treatment Need (IOTN). Index of Orthodontic Treatment Need (IOTN) was first developed by Brook and Shaw (1989) as a system for grading malocclusions, has 2 components, AC (Aesthetic Component) that shows patient's subjective needs and DHC (Dental Heath Component) that reveals objective needs for orthodontic treatment.

The research subjects were orthodontic patients at Post Graduate Orthodontic Clinic Faculty of Dentistry Universitas Padjadjaran from year 2009 to 2010 . The samples were taken in the form of dental study models and anterior dental scale photographs of orthodontic patients at Post Graduate Orthodontic Clinic Faculty of Dentistry Universitas Padjadjaran. Samples taken are patients who came to receive orthodontic treatment in period year 2009 to 2010 which fulfilled the inclusion criteria: Age above 11 years old with fully erupted maxillary canine, male and female, study models in good condition and available, anterior dental scale photographs available.

\section{RESULTS}

A total of 109 orthodontic patients at Post Graduate Orthodontic Clinic Faculty of Dentistry Universitas Padjadjaran from year 2009 to 2010 participated in the study. Samples consist of 80 females and 29 males.

As we can see in the Table 1 and Figure 1 above by using the DHC, 12.85 percent of the patients were assigned to the no / little need, 27.52 percent to borderline need and 59.63 percent to a need for orthodontic treatment. Orthodontic treatment need according to aesthetic Table 1. Distribution of DHC scores of sample, $n=109$

\begin{tabular}{ccc}
\hline DHC & $\mathbf{n}$ & $\%$ \\
\hline No / little need (1-2) & 14 & 12.85 \\
Borderline (3) & 30 & 27.52 \\
Need (4-5) & 65 & 59.63 \\
\hline Total & 109 & 100.00 \\
\hline
\end{tabular}

Table 2. Distribution of AC scores of sample, $n=109$

\begin{tabular}{ccc}
\hline AC & $\mathrm{n}$ & $\%$ \\
\hline No / Little need (1-4) & 54 & 49.54 \\
Borderline (5-7) & 19 & 17.43 \\
Need (8-10) & 36 & 33.03 \\
\hline
\end{tabular}

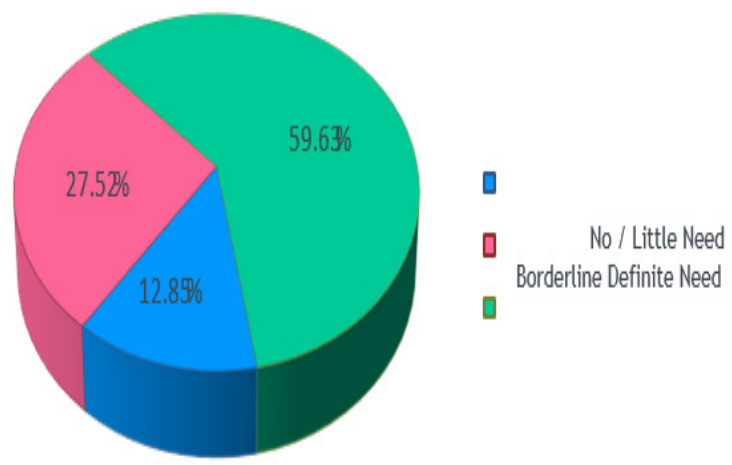

Figure1 Distribution of DHC scores of orthodontic patients who came to receive treatment in Post Graduate Orthodontic Clinic Faculty of Dentistry Universitas Padjadjaran period 2009 to 2010 


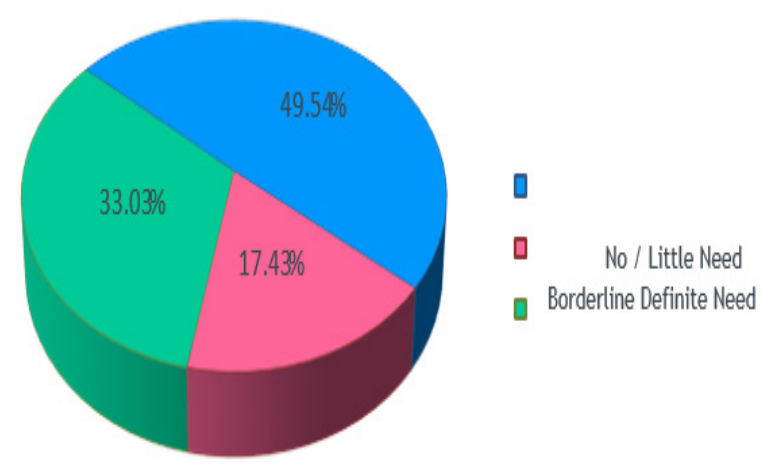

Figure 2. Distribution of AC scores of orthodontic patients who came to receive treatment in Post Graduate Orthodontic Clinic Faculty of Dentistry Universitas Padjadjaran period 2009 to 2010

impairment is shown in Table 2 and Figure 2. In 49.54 percent of the patients, the treatment need is either slight or not indicated according to the AC. Over 17.43 percent had a borderline need, while 33.03 percent were considered to have a definite treatment need by using the AC.

\section{DISCUSSION}

Measuring and recording the severity and prevalence of malocclusion is not only important for evaluating the occlusal status of subjects in a community and establishing the treatment priority, but it can be used as an epidemiological tool for preventive procedures or for training orthodontic specialists. Because of the demand of orthodontic treatment is increasing, this need highlights the importance of screening methods and epidemiological studies in order to obtain knowledge of the prevalence malocclusion and the need for orthodontic treatment. ${ }^{13}$

Methods that describe, evaluate, and classify occlusion can basically be divided into qualitative and quantitative methods ${ }^{13,14}$, and are designed either for study cast measurements, clinical use, or both. ${ }^{15}$ Malocclusion assessment methods are designed for different purposes ${ }^{13}$, and are divided into diagnostic classification, epidemiological, treatment need or priority treatment outcome and complexity need indices. $3,14,16$

Occlusal indices have been commonly used to objectively assess orthodontic treatment need. The Index of Orthodontic Treatment Need (IOTN) was developed to identify individuals who would benefit from orthodontic treatment. It comprises a dental health component $(\mathrm{DHC})$ and an aesthetic component (AC). ${ }^{17}$ The Index of Orthodontic Treatment Need (IOTN) is gaining wide acceptance all around countries. It has proven to be valid, reliable and quick index to assess orthodontic treatment need. ${ }^{18}$ By determining DHC score according to the data that has been collected on 109 sample of orthodontic patients who came to receive treatment in Post Graduate Orthodontic Clinic Faculty of Dentistry Universitas Padjadjaran since 2009 until 2010, the highest percentage is $59.63 \%$ with 65 patients had definite need of treatment, where the rest of 30 patients which is $27.52 \%$ expressed borderline need of treatment and the lowest percentage is $12.65 \%$ with 14 patients were considered to no need or slight need of treatment. By using the AC score according to the data that has been collected on 109 sample of orthodontic patients who came to receive treatment in Post Graduate Orthodontic Clinic Faculty of Dentistry Universitas Padjadjaran since 2009 until 2010, the highest percentage is $49.45 \%$ with 54 patients expressed no need or slight need of treatment, meanwhile 36 patients which is $33.03 \%$ were considered to have a definite need of orthodontic treatment and the lowest percentage is $17.43 \%$ with 19 patients had borderline need of treatment.

In this study, more patients had malocclusions indicating definite need for orthodontic treatment according to DHC than the AC impairment. This may be because the scores of the $\mathrm{DHC}$ may have been exaggerated by the rank of displacement, which would give a high score in otherwise normal occlusion. ${ }^{19}$ The DHC score is based on a grade assigned to the single 'worst' occlusal trait, which makes it an easy and reliable index to use, but ignores the cumulative effect of a number of lesser occlusal deviations. As a result, it may underestimate the severity of malocclusion in some individuals. ${ }^{8}$

In addition, the standard photographs of the AC do not show common orthodontic problems such as open bite and reverse overjet. ${ }^{19}$ In general, assessment of aesthetic impairment is complex and difficult to measure. ${ }^{20}$ The $\mathrm{AC}$ alone failed to identify any subjects needing orthodontic treatment and must be accompanied with the DHC. However, the IOTN may be adequate for public health planning and epidemiological purposes. ${ }^{21}$ 
Based on gender, the number of female patients who seek orthodontic treatment at Post Graduate Orthodontic Clinic Faculty of Dentistry Universitas Padjadjaran from year 2009 to 2010 is 80 , therefore it is greater compared to the number of male patients who wanted to receive treatment which is 29. Physical appearance, including the dentition, is an important aspect of human activity, as one aims to be liked, respected or accepted by those around him/her. The uptake of orthodontic treatment is influenced by the desire to look attractive, the selfperception of dental appearance, self-esteem, gender, age and peer group norms. ${ }^{1}$ Hence in this study, more females asked for orthodontic treatment because of the greater concern for looking more attractive. Moreover, desire for orthodontic treatment is primarily influenced by demand and not always by need. ${ }^{22}$

From the discussion, we can conclude that according to DHC, patients with definite need for treatment are the highest percentage among patients who seek orthodontic treatment at Post Graduate Orthodontic Clinic Faculty of Dentistry Universitas Padjadjaran. On the other note, according to $\mathrm{AC}$, patients with no need or little need for treatment are the highest percentage among other patients who seek orthodontic treatment.

\section{CONCLUSION}

$t$ DHC and AC scores from IOTN index of orthodontics patients who received orthodontic treatment in Post Graduate Orthodontic Clinic are: For DHC, the highest percentage is $59.63 \%$ with 65 patients expressed definite need of treatment, while $27.52 \%$ with 30 patients expressed borderline need of treatment and the lowest percentage is $12.85 \%$ with 14 patients expressed no need or little need of treatment; for $\mathrm{AC}$, the highest percentage is $49.54 \%$ with 54 patients were considered to have no need or little need of treatment, while $33.03 \%$ with 36 patients expressed definite need of treatment and the lowest percentage, $17.43 \%$ expressed borderline need of treatment.

\section{REFERENCES}

1. Abu Alhaija ESJ, Al-Nimri KS, Al-Khateeb
SN. 2004. Orthodontic treatment need and demand in 12-14 years old North Jordanian school children. Europ J Orthod. 26(6):261263.

2. Ngom PI, Diagne F, Dieye F, Diop-Ba K, F. Thiam F. Orthodontic treatment need and demand in Senegalese school children aged 12-13 years: an appraisal using IOTN and ICON. Angle Orthodontist. 2006;77:323-330.

3. Reichmuth $M$, Greene K, OrsiniM, Cisneros $G$, King $G$, Kiyak A. Occlusal perceptions of children seeking orthodontic treatment: impact of ethnicity and socioeconomic status. American Journal of Orthodontics and Dentofacial Orthopedics. 2005:128:575-82.

4. Padisar P, Mohammadi Z, Nasseh R, Marami A. The use of orthodontic treatment need index (IOTN) in a Referred Iranian Population. Res J Biological Scien 2009;4(4):438-43.

5. Kok YV, Mageson P, Harradine NWT, Sprod AJ. Comparing a quality of life measure and the Aesthetic Component of the Index of Orthodontic Treatment Need (IOTN) in assessing orthodontic treatment need and concern. J Orthod. 2004;31:312-318.

6. Mugonzibwa EA, Kujipers-Jagtman AM, Van T, Hof MA, Kikwilu EN. Need for orthodontic treatment among Tanzanian children. East African Med J. 2004;81(1):10-5.

7. Bernabé E, Flores-Mir C. Normative and selfperceived orthodontic treatment need of a Peruvian university population. Head Face Med. 2006 Aug 3;2:22.

8. Souames M, Bassigny F, Zenati N, Riordan, M.L Boy-Lefevre. Orthodontic treatment need in French schoolchildren: an epidemiological study using the Index of Orthodontic Treatment Need. Europ J Orthod. 2006;28:605-9.

9. Josefsson $\mathrm{E}$, Bjerklin $\mathrm{K}$, Lindsten $\mathrm{R}$. Malocclusion frequency in Swedish and immigrant adolescents-influence of origin on orthodontic treatment need. Europ J Orthod. 2007;29:79-87.

10. Hedayati Z, Fattahi HR, Jahromi SB. The use of index of orthodontic treatment need in an iranian population. J Indian Soc Pedo Preven Dentis. 2007;25:10-14.

11. Kuijpers MA, Kiekens RM. Research methods in dentistry. Assessment of orthodontic treatment need. Ned Tijdschr Tandheelkd. 
2005;112:206-10.

12. Ministry of Health Malaysia. Oral Health Division Annual Report. 2004. p. 41-52.

13. Thilander B, Pena L, Infante C, Parada SS, C. Mayorga. Prevalence of malocclusion and orthodontic treatment need in children and adolescents in Bogota, Colombia. An epidemiological study related to different stages of dental development. European Journal of Orthodontics. 2001;23:157-76.

14. Ovsenik M, Farčnik F, Verdenik I. Comparison of intra-oral and study cast measurements in the assessment of malocclusion. Europ $\mathrm{J}$ Orthod. 2004;26:273-7.

15. Ovsenik M. 2007. Assessment of malocclusion in the permanent dentition: reliability of intraoral measurements. Europ J Orthod 29:654-59.

16. Profitt. Contemporary orthodontics $4^{\text {th }}$ ed. Mosby Elsevier Westline Industrial Drive,
Missouri. 2007. p. 3-167.

17. Soh J, Sandham A. Orthodontic treatment need in Asian Adult Males. Angle Orthodontist, 2004;74(6):769-773.

18. Hassan AH. Orthodontic treatment need in the western region of Saudi Arabia. Head Face Med. 2004;2:2

19. Al-Sarheed M, Bedi R, Hunt NP. Orthodontic treatment need and self-perception of 11-16-year-old Saudi Arabian children with a sensory impairment attending special schools. J Orthod. 2003;30:39-44.

20. Tausche E, Luck O, Harzer W. Prevalence of malocclusions in the early mixed dentition and orthodontic treatment need. European J Orthodontics. 2004;26:237-44.

21. Hamdan AM, Al-Omari IK, Al-Bitar ZB. Ranking dental aesthetics and thresholds of treatment need: Acomparison between patients, parents, and dentists. Europ J Orthod. 2007;29:366-71. 